\title{
A SUBVERSÃO PELA TRADIÇÃO DE ISAK DINESEN: ANIMISMO, BRUXAS E STORYTELLING EM “THE DELUGE AT NORDERNEY"
}

Sofia Osthoff Bediaga ${ }^{1^{*}}$

Suzi Frankl Sperber ${ }^{1 * *}$

${ }^{1}$ Universidade Estadual de Campinas, Campinas, SP, Brasil

\section{Resumo}

O presente artigo tem como objetivo investigar de que modo a autora Isak Dinesen (pseudônimo e personagem viva de Karen Blixen) utiliza certos recursos para invocar a memória das tradições pagãs europeias. Entre eles, há o animismo, em que a natureza, especialmente o mar, tem agência e intenção, interferindo com e manipulando o enredo - remetendo ao sistema ontológico animista, que caracteriza o modo de pensar do paganismo. Há também o emprego do storytelling, modo como os conhecimentos são transmitidos entre as gerações por essas populações, e a presença constante da figura da bruxa. Ao empregar esses elementos em sua escrita, Dinesen cria um tipo peculiar de modernismo que subverte as leis da composição literária clássica através da retomada de outro tipo de tradição, que há séculos questiona e resiste ao status quo.

Palavras-chave: Isak Dinesen; Karen Blixen; Animismo; Bruxa; Storytelling.

\section{ISAK DINESEN'S SUBVERSION BY TRADITION: ANIMISM, WITCHES AND STORYTELLING IN “THE DELUGE AT NORDERNEY”}

\begin{abstract}
This article intends to investigate in what ways Isak Dinesen (Karen Blixen's pseudonym and living character) employs certain features to invoke the memory of the European pagan traditions. Among them is animism, in which nature, specially the sea, has agency and intention, interfering
\end{abstract}

\footnotetext{
* Mestranda em Teoria e História Literária pela Universidade Estadual de Campinas. É bacharel em Letras: Português-Russo pela Universidade Federal do Rio de Janeiro, tendo cursado um semestre na Universidade Livre de Berlim. Seu e-mail é: sofia.osthoff@gmail.com. ORCID: https://orcid.org/0000-0002-5242-8805.

${ }^{* *}$ Livre-docente e titular da Universidade Estadual de Campinas. Doutora, mestra e graduada em Letras pela Universidade de São Paulo. Foi coordenadora do Núcleo Interdisciplinar de Pesquisas Teatrais (LUME). Tem experiência na área de Letras, com ênfase em Teoria Literária, atuando principalmente nos seguintes temas: literatura brasileira, literatura comparada, hermenêutica, Guimarães Rosa, teatro - pesquisa e ação dramática, "Dramaturg". Coordenadora do GT Literatura e Sagrado (ANPOLL) e Coordenadora do Simpósio Literatura e Dramaturgia: entre o palco e a academia (ABRALIC). Atualmente desenvolve pesquisas sobre a obra de João das Neves e: Pulsão de ficção, mímesis de si e dramaturgia de si na horizontalidade. Seu e-mail é: sperbersuzi@ hotmail.com . ORCID: https://orcid.org/0000-0003-2862-394X .
} 
with and manipulating the plot - reminding us of the animist ontological system that characterizes the pagan worldview. There is also storytelling, which is used to pass on knowledge among different generations in these populations, and the constant presence of the witch figure. By employing these elements in her writing, Dinesen creates a peculiar type of modernism that subverts the laws of classical literary composition through the revival of another kind of tradition that has been questioning and resisting the status quo for centuries.

Keywords: Isak Dinesen; Karen Blixen; Animism; Witch; Storytelling. 
Isak Dinesen, pseudônimo e personagem viva de Karen Blixen (1885-1962), é célebre por ser considerada uma storyteller moderna. Em diversos momentos, em seus escritos e entrevistas, recusa o título de escritora e afirma: "Eu sou uma contadora de histórias, e nada além disso" (ARENDT, 1968, p. 97, nossa tradução $^{1}$ ). Suas obras, escritas inicialmente em inglês e depois reescritas em sua língua materna, o dinamarquês, ambientam-se geralmente nos séculos XVIII e XIX, e carregam uma saudade romântica do passado.

Dinesen, entretanto, não era uma escritora anacrônica: seu estilo, inspirado fortemente pelos gêneros da oralidade, mas também pela literatura moderna, carrega uma máscara daquilo que já foi enquanto trata de temas atuais. Sua recepção calorosa pelo público e pela crítica estadunidenses, país que talvez represente com mais força a modernidade, é prova de que ela estava bem de acordo com seu tempo ${ }^{2}$. Com sua base na literatura moderna, Dinesen era muito consciente e aberta sobre seu processo de escrita - compunha meticulosamente suas obras, empregando recursos linguísticos para criar os efeitos desejados e discutindo esse processo ao longo da escrita, fazendo com frequência uso da metalinguagem.

Dois recursos utilizados constantemente em suas obras são o animismo e a personificação. O espaço, o cenário, a natureza - aquilo que costuma ser tratado como objetos inanimados, o background das histórias - ganham vida em suas obras. Esses recursos não são, para Dinesen, meras figuras de linguagem: as coisas não só parecem vivas poeticamente, mas literalmente agem no curso da história, contribuindo para o enredo, demonstrando intenção e poder. Para Tamar Yacobi, no artigo "Plots of Space: World and Story in Isak Dinesen", o animismo e a personificação são mais que recursos porque expõem uma perspectiva em que o ser humano não é protagonista, e que o espaço age de um modo holístico, complexo e intricado para criar a história do mundo (YACOBI, 1991).

A novela "The Deluge at Norderney" é um ótimo exemplo para demonstrar como o animismo é utilizado por Dinesen, visto que o enredo possui como principal agente o Mar do Norte. Além disso, é possível, através dessa novela, estabelecer uma ponte entre esse recurso e a tão discutida oralidade da autora. Para isso, será criada uma relação entre o animismo de Dinesen com o sistema ontológico animista dos povos tradicionais dinamarqueses, ou seja, o modo como sua concepção de mundo é organizada, levando em conta que seus conhecimentos eram transmitidos, justamente, através do contar histórias.

"The Deluge at Norderney" faz parte do primeiro livro publicado por Dinesen, Seven Gothic Tales. Tem aproximadamente 70 páginas e consiste em uma narrativa principal com diversas pequenas histórias inseridas ao longo do texto. A novela é introduzida pelo seguinte cenário contraditório: "No primeiro quarto do último século, os resorts à beira-mar tornaram-se moda, mesmo naqueles países da Europa do Norte em que, para suas populações, o mar havia até então cumprido o papel do diabo, do frio e voraz inimigo hereditário da humanidade" (DINESEN, 2002, p. 121, nossa tradução ${ }^{3}$ ).

A novela se desdobrará em um desses "seaside resorts": a cidade de Norderney, na Alemanha, que virou um famoso destino da alta-sociedade pela sua aura de 
perigo, suas histórias sobre as tempestades e o mar imperdoável, suas ruínas do que fora destruído pelo clima hostil. O espírito romântico da época se deleitava com isso, e todas as pessoas "da moda" passavam seus verões lá, excitadas para ter um vislumbre - a uma distância segura - da natureza selvagem, observar as ondas indomáveis da costa, fazer piqueniques no entorno de uma embarcação naufragada.

Toda essa descrição, é claro, não é feita sem ironia: a alta-sociedade, ao romantizar esse lugar hostil onde apenas habitavam pescadores e usá-lo como um destino de verão, desfrutando nele de bailes, jogos de azar e flertes, mostra um fascínio desrespeitoso, visto que subestima o poder de destruição do mar. Até mesmo os locais passaram a participar dessa fantasia: "Até mesmo os camponeses e pescadores de Norderney aprenderam a olhar para o terrível e infiel monstro cinza a oeste dele como algum tipo de 'senhor da diversão'” (DINESEN, 2002, p. 121, nossa tradução $\left.{ }^{4}\right)$.

O majestoso Mar do Norte - descrito nessa introdução como "diabo, frio e voraz inimigo hereditário da humanidade, terrível e infiel monstro cinza" (nossa tradução $0^{5}$ - cuja força sempre foi temida e reverenciada pelos locais, é reduzido a um objeto de entretenimento, como um leão em um circo. Sua vivacidade, sua agência, sua capacidade de mudar o destino de quem cruza seu caminho são consideradas como crenças populares, superstições - algo que, apesar de ser poético e ter feito sentido em algum momento da história, não deve ser temido pelo homem moderno.

Esse desacato, entretanto, não dura muito: no fim do verão de 1835 houve uma combinação de fatores climáticos, que ocorre a cada cem anos, que fez com que o mar quebrasse os diques que protegiam a cidade e a invadisse com toda força, subindo, aos poucos, até o telhado das casas, e destruindo tudo que entrasse em seu caminho.

Diante desse cenário de destruição, o famoso Cardeal Hamilcar von Sehestedt, figura proeminente na Igreja Católica, que estava morando em Norderney nos últimos anos com a tarefa prodigiosa de escrever o Terceiro Testamento, assume uma postura heroica e altruísta, arriscando sua própria vida para salvar a população local e os turistas. Durante o último resgate antes do anoitecer, em um ato de coragem, ele, outras três pessoas e um cachorro cedem seus lugares em um barco para uma família e acabam encontrando-se em um celeiro prestes a colapsar, esperando a morte ou o resgate que viria apenas ao amanhecer. Para passar o tempo, decidem se entreter com histórias.

A história de Miss Malin Nat-og-Dag, "solteirona” rica que, apesar de ter vivido sua vida de acordo com a mais rígida moral protestante, enlouqueceu "por escolha” e acredita agora ter sido a mais célebre prostituta de seu tempo, é contada pelo narrador da novela e será vista em detalhes mais adiante no presente artigo. Em seguida, o jovem Jonathan Maersk fala sobre sua vida e como passou de simples filho de um capitão de navio morando em uma cidade pequena em sintonia com a natureza, para o mais célebre "man of fashion" de Copenhague, cuja misantropia e melancolia eram admiradas e imitadas por toda a alta-sociedade. A quarta personagem, a jovem Calypso von Platten Hallermund, sofria do problema oposto ao de Jonathan: ser invisível. Miss Malin conta a história da 
moça, que foi criada por seu tio, famoso poeta e matemático que acreditava que tudo de ruim se encontrava no sexo feminino e vivia em um castelo de ambiência gótica onde mantinha uma escola para meninos e onde todos ignoravam a presença da moça. Esta, entretanto, passa por uma experiência de libertação e vai morar com Miss Malin, sua madrinha, e ambas vão juntas para Norderney. Miss Malin, durante a situação de ameaça e horror, considera que os opostos se unam e sugere que os dois jovens se casem, e o Cardeal realiza a cerimônia.

Há, ao longo da narrativa, diversas discussões sobre arte, filosofia, religião e, no final, quando o jovem casal dorme, há uma revelação chocante: na verdade, o homem no celeiro não era o Cardeal Hamilcar von Sehestedt, mas seu ajudante, Kasparson, ator e aventureiro, brilhante e intelectual, cuja empreitada recente teria sido acompanhar o clérigo em sua histórica missão. Ao haver o colapso da casa em que ambos moravam, Kasparson, sabendo que apenas um deles sobreviveria e que o Cardeal cederia sua vida pela dele - visto que era tão nobre -, assassina-o, e decide exercer o grande papel de sua vida ao se fazer passar pelo Cardeal. A novela termina com a água chegando aos pés das personagens e a luz da manhã aparecendo, ao que Miss Malin cita as Mil e Uma Noites: “'Nesse momento da narração', ela disse, 'Scheherazade viu aparecer a manhã e, discreta, se calou"' (DINESEN, 2002, p. 188, nossa tradução6).

Para retomarmos a argumentação do presente artigo, voltemos ao início da novela. $\mathrm{O}$ dia anterior à tempestade é descrito com a maestria habitual de Dinesen: como uma pintura, a autora vai colorindo o cenário com tons peculiares, criando uma atmosfera de tensão e estranhamento - sem perder sua beleza. $\mathrm{O}$ ar - "de uma estranha, luminosa, sulfúrica obscuridão" (DINESEN, 2002, p. 122, nossa tradução $^{7}$ ) - parece prestes a receber uma aparição do Diabo. O sol, grande símbolo da razão, do Iluminismo, daquilo em que se baseia o homem moderno e que o protege, "se pôs em uma confusão de luz, um vermelho fosco como o alvo sobre a alameda" (DINESEN, 2002, p. 123, nossa tradução $0^{8}$ ), desse modo perdendo sua imposição e servindo como um alvo prestes a ser acertado pelas forças do mar.

"Naquela noite, as pessoas que não foram impedidas de dormir pela batida de seus próprios corações acordaram, aterrorizadas, por um rugido novo, aproximando-se rapidamente. Poderia seu mar cantar agora nessa voz?" (DINESEN, 2002, p. 123, nossa tradução ${ }^{9}$ ) - o mar é um animal selvagem, impossível de ser domado: nunca foi e nunca será "their sea". O selvagem invade a civilização de diversas formas simbólicas: o barulho impede os pensamentos, o vento arranca roupas, as ondas atingem o céu. $\mathrm{O}$ ar, "frio e amargo", mostra a sede de vingança da natureza diante daqueles que a subestimaram.

Depois da tempestade, a massa de água rompe os diques e há o dilúvio. Casas, fazendas, tudo que era mais sólido nas vidas dos locais desmorona-se como castelos de cartas. "O Mar do Norte viera visitá-los". Por ter ocorrido no verão, “o dilúvio assumiu o caráter de uma terrível e sinistra piada" (DINESEN, 2002, p. 124, nossa tradução ${ }^{10}$ ).

Essa descrição da natureza, especialmente do mar, coloca-a como viva, possuidora de agência e de intenção, e até mesmo de sentimentos que consideramos 
humanos - o mar é inclusive capaz de fazer piadas. Como dito acima, Yacobi (1991) desenvolve a ideia de que esse animismo não é apenas uma figura de linguagem, mas um modo de enxergar o mundo como vivo e agente. Essa visão de Dinesen elaborada por Yacobi aproxima-se não apenas ao animismo da linguagem, mas aos sistemas ontológicos animistas, que a antropologia vem estudando com especial atenção nas últimas décadas.

$\mathrm{O}$ animismo consiste em um modo de vida em que os seres humanos se enxergam como compartilhando uma interioridade com seres que nós, ocidentais, consideramos como não humanos, que, por sua vez, são vivos e plenos de intenção. Segundo Philippe Descola, "em sistemas animistas, a continuidade de relações entre humanos e não humanos que é permitida pela sua interioridade comum anula a descontinuidade introduzida pela sua diferença física" (DESCOLA, 2014, p. 83, nossa tradução $\left.{ }^{11}\right)$. Não humanos são, portanto, tratados como humanos (DESCOLA, 2014), pois compartilham uma alma, uma essência interior, apesar de seus corpos serem diferentes.

Esse sistema ontológico, que se encontra em diversas populações ao redor do mundo, se distingue do sistema ontológico da modernidade, o naturalismo. Este parte do princípio de que há uma divisão entre o que é natural e o que é cultural, e de que há uma natureza única, mas diversas culturas e pontos de vista. O natural é aquilo que não foi tocado pelo ser humano, e cujo desenvolvimento ocorre independentemente da agência deste, não podendo sofrer influências, enquanto o cultural é onde há livre-arbítrio, capacidade de mudanças segundo a vontade humana. Não humanos, nesse sistema, são definidos pela sua falta de humanidade (DESCOLA, 2014).

Para o antropólogo Tim Ingold, o animismo não é apenas um modo de pensar o mundo atribuindo vida e espírito ao que está inerte, mas é uma prática de estar vivo nele. É ser altamente sensível a um ambiente que está sempre em fluxo, no qual não há objetos animados, mas coisas que agem (INGOLD, 2014). "Filósofos têm ruminado amplamente sobre a condição de ser no mundo. Animismo, entretanto, diz respeito ao que significa estar vivo para ele. Estar vivo para o mundo é, em resumo, ser senciente. Não é possível, entretanto, ser senciente em um mundo que não sente" (INGOLD, 2014, p. 224, nossa tradução ${ }^{12}$ ).

$\mathrm{O}$ animismo, como dito anteriormente, se encontra em diversas partes no mundo. Na Europa, é o sistema ontológico no qual se baseiam os povos pagãos, que sofreram muitas perseguições desde a introdução do cristianismo, a mais forte e sanguinária dessas tendo sido a caça às bruxas nos séculos XVI e XVII. Apesar de esses povos terem tido suas populações reduzidas drasticamente, ainda hoje é possível encontrar seus descendentes em diversas partes da Europa, assim como muitas de suas crenças e práticas, que se mantiveram especialmente entre populações rurais (STARHAWK, 2018).

Mesmo entrando em contato com o pensamento naturalista moderno, o pensamento animista continua existindo, pois não é um estágio pelo qual é necessário passar antes de chegar a uma sociedade mais avançada, como afirma o evolucionismo histórico, mas uma disposição do pensamento tão válida e atual 
quanto a ocidental moderna. Assim, por mais que a modernidade tenha tentado acabar com esse modo de pensar por meio da caça às bruxas e de outros mecanismos de ridicularização e desvalorização do pensamento animista, ele resistiu em diversas populações, e manteve-se representado pela figura folclórica da bruxa.

Isak Dinesen era fascinada pelas bruxas - estas aparecem em boa parte de suas histórias (das sete narrativas do livro Seven Gothic Tales, há alusões a bruxas em seis), e em diversos momentos a autora própria se identificava como uma bruxa. Em um relato de um amigo pessoal:

Quando eu a conheci, e quando outras pessoas a conheceram, ela disse que morrera muitos anos atrás, e no modo mais arrepiante e para a confusão e desespero de seus amigos, ela se definia dentro da tradição cristã como uma bruxa, uma serpente, a amante do Diabo. Isso não era um capricho, não foi uma piada contada uma vez, mas algo que ela clamava como sendo seu direito, a nota essencial em todo texto (HENRIKSEN, 1985, p. 397, nossa tradução ${ }^{13}$ ).

A personagem que "interpreta o papel" da bruxa em "The Deluge at Norderney" é Miss Malin. Seu enorme nariz, sua loucura e excentricidade, seu desprezo pela moral cristã e apreço pelo pecado trazem lembranças a essa figura, além de que há duas alusões explícitas a esta dizendo respeito à personagem: "Ela sempre se parecera com uma bruxa" (DINESEN, 2002, p. 139, nossa tradução ${ }^{14}$ ) e "disse Miss Malin, com uma risadinha verdadeiramente de bruxa" (DINESEN, 2002, p. 152 , nossa tradução ${ }^{15}$ ).

A história de Miss Malin é bem peculiar: herdeira de um sobrenome de grande peso, porém de pequena fortuna, mostrava propensões dramáticas desde cedo, sendo sempre cheia de caprichos. Quando jovem, estudava filosofia e enxergava as paixões humanas com desdém. Devido à sua criação protestante, guardava sua castidade com um fervor desproporcional: "Ela tomou a atitude não apenas de defesa, mas de uma ofensiva das mais audaciosas. Fantástica por natureza, ela não via nenhum motivo para temperança, e subiu seu preço fantasticamente" (DINESEN, 2002, p. 135, nossa tradução ${ }^{16}$ ). Assim, qualquer investida de um homem, para ela, era como uma tentativa de estupro, e a fantasia que criou ao redor de seu "valor" fez com que ela, apesar de não ser bonita, fosse considerada uma das moças mais belas da alta-sociedade.

Aos vinte e sete anos de idade, decidiu enfim casar-se, e escolheu, diante de todos os seus admiradores, o príncipe mais desejado pelas jovens, e que se apaixonou por Miss Malin apenas porque seu "preço" o intrigava - e ele era um grande amante de charadas. A felicidade do jovem casal foi, porém, arrasada pela morte do amante em uma batalha, logo após o noivado. Esse evento traumático foi, então, o que lhe faltava para desistir de vez da ideia de casar-se.

Aos cinquenta anos, Miss Malin recebeu uma grande fortuna inesperada de herança. Essa idade, segundo a narrativa, é quando ocorre "a transferência do serviço ativo da vida [...] para o estado meramente passivo de uma espectadora. Um peso caiu dela; ela voou para o poleiro mais alto e cacarejou um pouco. [...] 
Em seu riso de libertação com certeza havia certa loucura" (DINESEN, 2002, p. 138, nossa tradução ${ }^{17}$ ).

Desse modo, Miss Malin, louca por sua própria escolha ou por algum capricho dela, passou a acreditar que ela fora a maior cortesã de seus tempos, e que sua grande fortuna teria sido obtida pelos seus pecados. Passou, portanto, a contar inúmeras histórias sobre seus amantes e suas aventuras, vivendo, em retrospectiva, uma vida de intensas emoções, que entrava em completo contraste com seu antigo protestantismo fervoroso. Desde sua juventude até a velhice, portanto, Miss Malin usa da fantasia para alterar a realidade, exercendo uma espécie de mágica da palavra para conseguir o que quer: uma bruxa que conta histórias em vez de conjurar feitiços.

Uma passagem importante para entendermos Miss Malin é a descrição feita no primeiro momento em que ela aparece na narrativa: no barco, "[ela dava] aquela impressão de selvajaria que, em uma era e em uma sociedade pacíficas, apenas a aristocracia evanescente e decadente pôde se dar o luxo de manter" (DINESEN, 2002, p. 128, nossa tradução ${ }^{18}$ ), e logo mais é comparada a uma tigresa que é especialmente perigosa por parecer ser domada. Há, nessa personagem, portanto, uma curiosa combinação entre uma nobre, uma bruxa e uma contadora de histórias, que além de tudo é selvagem e louca - uma personagem que abriga o que há de mais resistente à modernidade.

Isak Dinesen também reivindicava para si o lugar de bruxa e conteuse. Há uma forte relação histórica entre ambas: as tradições dos povos pagãos, que não possuíam escrita, eram transmitidas principalmente através de histórias, fossem mitos, lendas, fábulas ou contos de fadas. Nessas narrativas orais concentrava-se o conhecimento que seria transmitido através das gerações. Sobre as lendas, os folcloristas Reimund Kvideland e Henning K. Sehmsdorf escrevem, na introdução de seu livro Scandinavian Folk Belief and Legend: "Entretenimento é uma dimensão importante em todos os gêneros que discutimos [lendas, memorats, chronicats], mas é raramente, ou nunca, primária. [...] Ao recitar e falar sobre lendas e experiências supernaturais, o povo transmite e reafirma crenças coletivas" (KVIDELAND; SEHMSDORF, 1999, p. 21, nossa tradução ${ }^{19}$ ).

A bruxa à qual Dinesen se refere, tanto em suas histórias quanto em sua vida pessoal, não é literalmente qualquer pessoa que segue uma religião pagã, mas é a figura que, no imaginário cristão, representa a conservação dos conhecimentos tradicionais desses povos e a recusa em se submeter à moral cristã sendo, por isso, considerada "amante do Diabo". Além disso, ao preservar conhecimentos tradicionais, a bruxa também representa aquilo que o pensamento moderno quer apagar - a crença em "superstições", em "magia", em tudo aquilo que se encontra longe do alcance da razão e da ciência.

A ativista neopagã Starhawk, em seu artigo "Magia, visão e ação", chama a atenção ao fato de que as perseguições às bruxas tiveram seu auge nos séculos XVI e XVII, ou seja, na época em que o pensamento moderno se implementava com mais força. Assim, segundo ela, essas perseguições 
Surgiram como uma maneira de contestar e erradicar a antiga percepção de que o mundo está vivo e de que a vida é dotada de percepção e consciência - não necessariamente a mesma percepção ou consciência que a sua ou minha, mas a vida tem uma presença e tem um ser (STARHAWK, 2018, p. 57).

Segundo a autora, essa percepção nunca desapareceu em diversos lugares do globo, e estabelece que é necessário manter um relacionamento de reciprocidade com o mundo natural, o que vai contra a sensibilidade capitalista que surgia na época, "que consistia em extrair valor sem restrições" (STARHAWK, 2018, p. 57):

A perseguição às Bruxas nos deixou um legado que cortou nossa sensibilidade em relação a uma Terra viva. É difícil para a gente se abrir e escutar a Terra falando sem sentir medo ou sem, ao menos, sentir que estamos fazendo algo suspeito e perigoso ou talvez apenas algo ridículo, algo que obviamente não é verdadeiro (STARHAWK, 2018 p. 59).

A filósofa Isabelle Stengers, no livro Reativar o animismo, aponta para o fato de como os efeitos das caças às bruxas permanecem até hoje quando ridicularizamos termos como "bruxas" e "magia" e quando enxergamos esse evento com um "orgulho moderno da capacidade de interpretar tanto a bruxaria quanto a caça às bruxas em termos de construções, crenças sociais, linguísticas, culturais ou políticas" (STENGERS, 2017, p. 9). Ao zombar dos que acreditavam (ou ainda acreditam) em bruxas, os modernos reforçam essa "operação de erradicação cultural e social", visto que "qualquer coisa que classifique a memória de tais operações como sem importância ou irrelevante só contribui para torná-las mais bem-sucedidas" (STENGERS, 2017, p. 9).

Ou seja, a bruxa representa a figura antissocial que é punida seja com a fogueira - nos séculos XVI e XVII, ou com a ridicularização, depois dessa época, por não se submeter à moral dominante -, seja com o cristianismo ou com o pensamento moderno. Nas histórias de Dinesen, aquelas personagens que representam essa figura, como Miss Malin, são sempre descritas como de algum modo selvagens, indomáveis, e agem de acordo com sua própria moral, sem se submeter a qualquer uma externa a elas ${ }^{20}$.

Há indícios, embora não provas, de que Dinesen teria entrado em contato com as tradições folclóricas dinamarquesas, visto que ela cresceu e viveu a maior parte de sua vida em uma propriedade rural, onde escreveu todos os seus livros. Embora essas práticas e crenças fossem mais marcantes entre as camadas mais baixas da sociedade rural, Kvideland e Sehmsdorf (1999) afirmam que "devemos lembrar que essas tradições coletivas pertenciam a todo o povo, incluindo os fazendeiros com terra, e que elas moldavam sua existência diária tanto quanto os pobres" (KVIDELAND; SEHMSDORF, 1999, p. 17, nossa tradução ${ }^{21}$ ).

Sobre o modo de viver e de enxergar o mundo dos povos nas áreas rurais da Escandinávia, após a chegada do cristianismo e até a industrialização, que ocorreu ao longo dos séculos XIX e XX,, Kvideland e Sehmsdorf (1999, p. 8, nossa tradução ${ }^{22}$ ) escrevem: "O povo vivia perto da natureza e acreditava que era 
parte dela. Na visão de mundo da população rural, crenças ensinadas pela igreja fundiam-se com aquelas nativas à Escandinávia e sobreviventes na tradição popular". Ou seja, mesmo considerando-se cristãos, o paganismo continuava vivo nas tradições folclóricas.

Os folcloristas escrevem também sobre essas crenças tradicionais, que podemos associar sem dificuldades ao animismo: "Percebendo seu ambiente diário em termos pré-científicos, mas eminentemente práticos, o povo respondia à natureza no modo como a experienciava, ou seja, como animada e possuindo vontade e, portanto, sendo capaz de ajudar humanos, mas também de machucá-los" (KVIDELAND; SEHMSDORF, 1999, p. 9, nossa tradução ${ }^{23}$ ).

Isak Dinesen, ao crescer no meio rural dinamarquês no fim do século XIX, pode ter entrado em contato com esse modo de pensar animista através das histórias contadas oralmente: lendas, contos de fadas, fábulas, entre outras formas, que compreendiam o arcabouço da tradição popular rural dinamarquesa. Sabendo que Dinesen reivindicava com muita veemência seu lugar de "storyteller" em oposição ao de "writer", podemos saber como essa influência das tradições orais não foi pequena. Sobre a relação entre a autora e as narrativas orais, há muitos estudos. Segundo a folclorista Merry Weed, não se pode dizer que ela fosse literalmente uma "storyteller", visto que

Dinesen nunca teve a oportunidade, até onde sabemos, de passar pela aprendizagem específica que a criação oral demanda, como mostram folcloristas. Além disso, seus manuscritos e cadernos de notas mostram uma reelaboração escrita meticulosa de seu material. [...] Em método de composição, Dinesen é literária (WEED, 1978, p. 28-29, nossa tradução ${ }^{24}$ ).

Porém, Weed (1978) afirma que é inegável a influência que diversas formas da oralidade, provindas de diferentes fontes, tiveram sobre seu estilo de escrita. Desde a infância, Dinesen contava histórias para sua família, possivelmente por influência de seu pai, que viajara o mundo e até mesmo publicou um livro sobre suas experiências. A autora também entrou em contato desde cedo com a obra de Hans Christian Andersen, escritor de contos de fadas autorais e amigo de seu avô, com os livros dos Irmãos Grimm e com as Icelandic Sagas, que narram o folclore islandês. Também era uma ávida leitora da literatura romântica dinamarquesa do século XIX, a qual valorizava as narrativas orais como expressão da cultura nacional. Não há registros de um contato com contadores de história propriamente ditos (WEED, 1978), mas há uma grande possibilidade de ela ter ouvido histórias desse gênero das pessoas que trabalhavam na propriedade de sua família, ou mesmo de seus próprios pais.

Mais tarde em sua vida, morou durante muitos anos em uma fazenda no Quênia, entrando em contato com as tradições orais da região, tanto as das mulheres quanto as dos homens (BLIXEN, 2001). Nesse período, entretinha suas visitas com histórias de sua autoria. A ficção que criava era de estilo e cenário europeu, mas o contato que ela teve com a cultura africana serviu para trazer uma nova luz a essa tradição que se perdia na Europa. Em seu texto autobiográfico Out of Africa, escreve: 
Eu sempre pensei que eu poderia ter feito sucesso no tempo da praga em Florença. As modas mudaram, e a arte de ouvir a uma narrativa perdeuse na Europa. Os nativos da África, que não podem ler, ainda a possuem [...]. Mas pessoas brancas, mesmo se elas sentem que precisam, não conseguem ouvir a um recital (BLIXEN, 2001, p. 194, nossa tradução ${ }^{25}$ ).

Diz-se do antropólogo que, ao entrar em contato com povos tão diferentes do seu, ele termina por inevitavelmente refletir sobre sua própria cultura. $\mathrm{O}$ contato de Dinesen com kikuyus e somalis teve esse efeito:

É como se ela, que é distante a ambos, historicamente separada de Boccaccio e culturalmente separada dos 'nativos' [do Quênia], assume uma linha de tradição em cada mão. A vitalidade da africana fluiu através dela, energizando a impotente história europeia, mas nunca se enroscando inteiramente nela (WEED, 1978, p. 27, nossa tradução ${ }^{26}$ ).

Influenciada por diversas formas da oralidade, assim como pela literatura ocidental, pois era uma ávida leitora, indo dos gregos clássicos aos estadunidenses contemporâneos, Dinesen formou um estilo próprio que, segundo a crítica de arte Bonnie Marranca, “juntou a saudade romântica de uma era anterior a uma sensibilidade modernista que se organizaria em volta das ideias de escrita, performance e Deus" (MARRANCA, 1986, p. 93, nossa tradução ${ }^{27}$ ).

Dinesen escrevia com muita consciência do processo, lapidando seu estilo com esmero para criar os efeitos desejados. Como um exemplo disso, Weed (1978) aponta como, no conto "Sorrow-Acre", Dinesen utiliza o contraste estilístico entre contos de fadas e lendas para descrever ambientes e personagens de modo a contribuir para o sentido da história. Assim, certos ambientes e personagens são descritos com um estilo similar aos contos de fadas, outros com um estilo similar às lendas, e isso cria um efeito especial sobre o leitor.

Isak Dinesen situa-se, portanto, no limiar entre uma storyteller e uma escritora. Embora não possamos dizer que ela narrava histórias oralmente à moda antiga, não podemos ignorar a força que essa tradição teve sobre sua escrita. Assim, em um mundo em que a arte da narrativa oral estaria se perdendo, como desenvolve Walter Benjamin (2014) em “O narrador”, Dinesen consegue encontrar um meio de mantê-la viva e atual, abraçando suas próprias contradições e se tornando uma "storyteller moderna", cuja composição é tanto oral quanto escrita, com todos os paradoxos que isso poderia trazer.

Em “The Deluge at Norderney”, Dinesen utiliza de certos recursos para criar uma atmosfera ligada à lenda: expõe um acontecimento que supostamente ocorreu de fato, com datas, lugares e pessoas específicas. Entretanto, há um tom exagerado, caricato, de uma história que provavelmente sofreu várias alterações ao longo dos anos, e que, portanto, não tem exatamente valor de documento, mas não obstante carrega a sabedoria acumulada de gerações.

O animismo e a personificação da natureza e dos objetos na novela nos remetem a essa sabedoria atemporal do não humano, aquilo que paira sobre nós, mas cuja linguagem, talvez, não consigamos entender por completo. As práticas 
pagãs tinham esse objetivo de decifrar a língua da natureza, e conversar de volta. Segundo Starhawk (2018, p. 55), "A natureza canta e fala, e o mundo inteiro se comunica conosco. Nisso, podemos reconhecer outra definição de magia: a magia seria a arte de se abrir e ouvir profundamente essa comunicação".

Dinesen cria, em suas histórias, uma atmosfera mágica, em que o mundo está vivo e senciente e, além de tudo, é capaz de alterar drasticamente as vidas das pessoas. Há uma passagem em que a personagem Jonathan narra uma conversa com seu pai, e este lhe diz: "Eu conheço uma cura para tudo: água salgada. / 'Água salgada?' perguntei-lhe. / 'Sim', ele disse, 'de um jeito ou de outro. Suor, ou lágrimas, ou o mar salgado"' (DINESEN, 2002, p. 154, nossa tradução ${ }^{28}$ ). O mar aparece na narrativa, portanto, como força destruidora, mas também de cura, se soubermos usá-la.

No fim da novela, Miss Malin percebe que seu vestido estava molhado. Ela e Kasparson olham para o chão do celeiro: "Uma figura escura, como de uma cobra longa e grossa, deitava-se sobre as tábuas, e um pouco abaixo, onde o chão inclinava ligeiramente, ela alargava-se em uma piscina negra que quase tocava os pés da menina adormecida [Calypso]. A água subira ao nível do sótão" (DINESEN, 2002, p. 187-188, nossa tradução ${ }^{29}$ ). É verdadeiramente intrigante como algo absolutamente real pode ser percebido como especial pelas duas personagens capazes de apreender o fantástico: Miss Malin e Kasparson, que olham para o chão do celeiro. A marca molhada, indício de que a água já atingira o cimo da construção em que se abrigavam, é vista como uma cobra. A serpente visível é isso mesmo nesse momento: a breve encarnação de uma Grande Serpente invisível, causal e atemporal, dona do princípio vital e de todas as forças da natureza. Eles poderão ser salvos (era o tempo anunciado para que uma embarcação ali chegasse para recolhê-los), ou poderá ser seu fim. É o tempo do relato, tempo de salvação ou de perdição... Enigma que permanece, enigma que representa o ouroboros, a serpente que morde seu rabo: representa começo e fim, "a circunferência vem aqui completar o centro para sugerir, segundo a expressão de Nicolás de Cusa, a ideia mesma de Deus" (CHEVALIER; GHEERBRANT, 1986, p. 927, nossa tradução $0^{30}$ ). Sutil, animizada, a espiritualidade se manifesta.

Em nível diferente, a água toma forma de uma cobra, animal que simboliza, na tradição cristã, o conhecimento. Entretanto, não é o conhecimento teórico e abstrato que ela representa, mas o prático, aquilo que se aprende com o corpo, com a experiência. No artigo "The Chronotopes of the Sea", Margaret Cohen (2006) fala sobre o cronótopo (que caracteriza, em Bakhtin, a dimensão poética da representação literária do espaço da "água azul", a água que se encontra no mar aberto. Segundo a autora, é no domínio desse elemento que as personagens entram em contato com os poderes violentos e imprevisíveis da natureza. É a desordem, é onde não se respeitam as leis humanas, onde ocorrem eventos implausíveis.

Cohen (2006) afirma, entretanto, que não há a ausência total de leis, mas que são seguidas as leis naturais em vez das humanas. 
As personagens que conseguem decifrar tais leis naturais o podem apenas com grande experiência. Sua experiência é obtida por prática direta. Não é um conhecimento encontrado em livros e, muitas vezes, se opõe a este. Ele se rende apenas àqueles que são fortes o suficiente para confrontar os poderes esmagadores da água azul e sobreviver seus perigos (COHEN, 2006, p. 653, nossa tradução ${ }^{31}$.

A água azul aparece na literatura como um modo de expor os limites do pensamento teórico e abstrato e colocar como essencial um tipo de conhecimento prático que é desvalorizado na sociedade ocidental, visto que não segue um raciocínio lógico e científico. Assim sendo, podemos relacionar as personagens que sabem lidar com a água azul com os povos pagãos que transmitiam seus conhecimentos não através de livros e estudos científicos, mas através das trocas de experiências que eram contidas nas histórias.

As personagens que aprendem a lidar com a água azul através da experiência têm sua coragem e exposição aos riscos recompensadas pela liberdade e a leveza de viver em um ambiente sem as regras conservadoras da sociedade. Segundo Cohen, o modernismo utilizou-se desse cronótopo para representar "liberdade artística em rebelião contra hierarquias sufocantes e ossificadas [...]. Virgina Woolf [em Ao farol] associa a liberdade da água azul à habilidade do texto de subverter as hierarquias opressivas da forma" (COHEN, 2006, p. 655, nossa tradução ${ }^{32}$ ).

Diferentemente de outros modernistas, a subversão de Dinesen, ao trazer a água azul para a cidade de Norderney, não ocorre diante da concepção de um estilo totalmente novo que enfrenta as "leis" da composição literária clássica utilizando recursos como "mudança aos trabalhos da mente, decronologização, forma espacial, limitação da perspectiva” (YACOBI, 1991, p. 449, nossa tradução ${ }^{33}$ ). A obra de Dinesen subverte a tradição literária da época ao criar um estilo que traz novidade e singularidade ao retomar a magia das histórias orais que, em termos de forma, parecem conservadoras, mas que apresentam sua rebeldia ao invocar uma tradição que resiste ao status quo há centenas de anos. Ao se colocar simbolicamente como storyteller, apesar de ser tecnicamente uma escritora, Dinesen mostra o potencial criativo e artístico das tradições orais e como elas podem ser colocadas lado a lado das tradições literárias.

Do mesmo modo, ao resgatar o paganismo, seja através do animismo ou da presença de bruxas em suas histórias, Dinesen mostra como essas tradições carregam um conhecimento sobre o mundo de importância e relevância extremas. Apesar de o pensamento moderno carregar uma ideia de progresso que nos impede de "olhar para trás", a não ser que seja apenas por uma curiosidade de historiador, Dinesen mostra como essas tradições nunca foram superadas ou se tornaram obsoletas. Pelo contrário, elas continuam vivas, ativas e criativas, assim como o Mar do Norte, e o ato de subestimá-las pode ser perigoso para nós, modernos.

Dinesen dizia que tinha três mil anos de idade (HENRIKSEN, 1985, p. 390). Durante milênios, a experiência e a sabedoria de centenas de gerações foram se acumulando e, enfim, tomaram vida na autora, que dissemina a presença dessa ancestralidade em suas histórias. "The Deluge at Norderney" carrega em sua nar- 
rativa essa subversão pela tradição de diversos modos: ao trazer vida e intenção à natureza através do animismo, ao evocar a bruxa através de Miss Malin e ao empregar um estilo de escrita que faça alusão às lendas, que carregavam o conhecimento de toda uma população. Isak Dinesen, a storyteller, revela um mundo que, apesar de ter sido encoberto pela modernidade, nunca deixou de existir, e se mantém vivo, pulsante e prestes a se fazer mostrar novamente, ensinando-nos a nunca o subestimar.

\section{Agradecimentos}

Agradecemos a Arthur Imbassahy, que revisou o conteúdo antropológico do presente artigo. Agradecemos também à CAPES pela bolsa de mestrado que tornou este artigo possível.

Notas

1. No original: "Je suis une conteuse, et rien qu'une conteuse" (ARENDT, 1968, p. 97).

2. Duas de suas obras foram adaptadas para o cinema com grande sucesso nos anos 1980, na Dinamarca com o filme Babettes gestebud [A festa de Babette] (1987) e nos Estados Unidos com Out of Africa [Entre dois amores] (1985). Há também uma linda adaptação homônima do conto "The Immortal Story" dirigida por Orson Welles, que é menos conhecida, mas não de menor qualidade que esses outros filmes.

3. No original: "During the first quarter of the last century, seaside resorts became the fashion, even in those countries of Northern Europe within the minds of whose people the sea had hitherto held the role of the devil, the cold and voracious hereditary foe of humanity" (DINESEN, 2002, p. 121).

4. No original: "The peasants and fisherman of Norderney themselves learned to look upon the terrible and faithless gray monster westward of them as upon some kind maître de plaisir" (DINESEN, 2002, p. 121).

5. No original: "devil", "cold and voracious hereditary foe of humanity", "terrible and faithless grey monster".

6. No original: "'A ce moment de sa narration,' she said, 'Scheherazade vit paraître la matin, et, discrète, se tut" (DINESEN, 2002, p. 188).

7. No original: "[of] a strange, luminous, sulphurous dimness" (DINESEN, 2002, p. 188).

8. No original: "went down in a confusion of light, itself a dull red like the target upon the promenade" (DINESEN, 2002, p. 123).

9. No original: "That night the people who were not kept awake by the beating of their own hearts woke up, terrified, by a new, swiftly approaching roar. Could their sea sing now in this voice?" (DINESEN, 2002, p. 123).

10. No original: "The North Sea had come to visit them" / "the deluge assumed the character of a terrible, grim joke" (DINESEN, 2002, p. 124).

11. No original: "in animic systems, the continuity of relations between humans and non-humans that is allowed by their common interiority overrides the discontinuity introduced by their physical difference" (DESCOLA, 2014, p. 83).

12. No original: "Philosophers have ruminated at length on the condition of being in the world. Animism, however, is about what it means to be alive to it. To be alive to the world is, in a word, to be sentient. It is not possible, however, to be sentient in an insentient world" (INGOLD, 2014, p. 224). 
13. No original: "when I met her, and when other people met her, she said that she had died many years ago, and in the most hair-raising fashion and to the confusion and despair of her friends, she defined herself within the Christian tradition as a witch, a serpent, the mistress of the Devil. This was not a whim, not a joke once uttered, but something she claimed as her right, the essential note on all text" (HENRIKSEN, 1985, p. 397).

14. No original: "Like a witch she has always looked" (DINESEN, 2002, p. 139).

15. No original: "said Miss Malin, with a truly witchlike little laugh" (DINESEN, 2002, p. 152).

16. No original: "She took the line, not only of defense, but of a most audacious offensive. Fantastical by nature, she saw no reason for temperance, and drove up her price fantastically high" (DINESEN, 2002, p. 135).

17. No original: "the transfer from the active service of life [...] to the mere passive state of a looker-on. A weight fell from her; she flew up to higher perch and cackled a little. [...] In her laughter of liberation there certainly was a little madness" (DINESEN, 2002, p. 138).

18. No original: "[she gave] that impression of wildness which, within a peaceful age and society, only the vanishing and decaying aristocracy can afford to maintain" (DINESEN, 2002, p. 128).

19. No original: "Entertainment is an important dimension in all the genres we have discussed [legends, memorats, chronicats], but it is rarely, if ever, primary. [...] In reciting and talking about legends and supranormal experiences, the folk transmit and reaffirm collective belief' (KVIDELAND; SEHMSDORF, 1999).

20. Miss Malin, mesmo ao seguir as regras de castidade do protestantismo, o faz de seu modo, exagerando a ponto de se recusar completamente a se casar, algo que seria esperado dela.

21. No original: "pobres it must be remembered that these collective traditions belonged to all the folk, including the landed farmers, and that it shaped their daily existence as much as that of the poor" (KVIDELAND; SEHMSDORF, 1999, p. 17).

22. No original: "The folk lived close to nature and believed they were a part of it. In the worldview of the rural population, beliefs taught by the church merged with those native to Scandinavia and surviving in folk tradition" (KVIDELAND; SEHMSDORF, 1999, p. 8).

23. No original: "Perceiving their daily environment in prescientific but eminently practical terms, the people responded to nature in the way they experienced it, namely as animate and possessed of will and thus capable of aiding humans but also of doing them harm" (KVIDELAND; SEHMSDORF, 1999, p. 9).

24. No original: "Dinesen never had the opportunity, as far as we know, to undergo the exacting apprenticeship that folklorists have shown oral creation to demand. Furthermore, her manuscripts and notebooks show meticulous written reworking of her material. [...] In method of composition, Dinesen is literary" (WEED, 1978, p. 28-29).

25. No original: "I have always thought that I might have cut a figure at the time of the plague of Florence. Fashions have changed, and the art of listening to a narrative has been lost in Europe. The Natives of Africa, who cannot read, have still got it [...]. But white people, even if they feel that they ought to, cannot listen to a recital" (BLIXEN, 2001, p. 194).

26. No original: "It is as if she, who is a stranger to both, historically separate from Boccaccio and culturally detached from the 'natives' [of Kenya], stands with a line of tradition in each hand. The vibrancy of the African flowed through her, energizing 
the impotent European story, but never becoming fully entangled in it" (WEED, 1978, p. 27).

27. No original: "joined the Romantic longing of an earlier age to a modernist sensibility that would organize itself around ideas of writing, performance, and God - the latter combining them in His capacity as the first storyteller, the first actor" (MARRANCA, 1986, p. 93).

28. No original: "I know of a cure for everything: salt water.' 'Salt water?' I asked him./ 'Yes,' he said, 'in one way or the other. Sweat, or tears, or the salt sea"' (DINESEN, 2002, p. 154).

29. No original: "A dark figure, like that of a long thick snake, was lying upon the boards, and a little lower down, where the floor slanted slightly, it widened to a black pool which nearly touched the feet of the sleeping girl [Calypso]. The water had risen to the level of the Hayloft" (DINESEN, 2002, p. 187-188).

30. No original: "la circunferencia viene aquí a completar el centro para sugerir, según la expresión de Nicolás de Cusa, la idea misma de Deus" (CHEVALIER; GHEERBRANT, 1986, p. 927).

31. No original: "The characters who are able to decipher such natural laws can only do so with long experience. Their experience is gained from hands-on practice. It is not a knowledge found in books, and is often opposed to it. It yields itself only to those who are strong enough to engage the overwhelming powers of blue water and survive its dangers" (COHEN, 2006, p. 653).

32. No original: "artistic freedom in rebellion against stifling, ossified hierarchies (...). Virginia Woolf [in To the Lighthouse] associates blue-water freedom with textuality's ability to subvert the oppressive hierarchies of form" (COHEN, 2006, p. 655).

33. No original: "shift to the workings of the mind, dechronologization, spatial form, perspectival limitation" (YACOBI, 1991, p. 449).

\section{Referências}

ARENDT, Hannah. Isak Dinesen: 1885-1963. In: ARENDT, Hannah. Men in Dark Times. Nova York: Harcourt, Brace \& World, 1968.

BENJAMIN, Walter. O narrador. In: BENJAMIN, Walter. Magia e técnica, arte e política: ensaios sobre literatura e história da cultura. Tradução de Sérgio Paulo Rouanet. 8. ed. São Paulo: Editora Brasiliense, 2014. p. 213-240.

BLIXEN, Karen. Out of Africa. Londres: Penguin Classics, 2001.

CHEVALIER, Jean ; GHEERBRANT, Alain. Dicionario de los símbolos. Barcelona: Editorial Herder, 1986.

COHEN, Margaret. The Chronotopes of the Sea. In: MORETTI, Franco (Org.). The Novel - Vol. 2: Forms and Themes. Princeton, Nova Jersey: Princeton University Press, 2006.

DESCOLA, Philippe. Between nature and culture. In: HARVEY, Graham (Org.). The Handbook of Contemporary Animism. Nova York: Routledge, 2014.

DINESEN, Isak. Seven Gothic Tales. Londres: Penguin Classics, 2002.

HENRIKSEN, Aage. The Empty Space Between Art and the Church. Scandinavian Studies, v. 57, n. 4, p. 390-399, outono, 1985.

INGOLD, Tim. Being alive to a world without objects. In: HARVEY, Graham (Org.). The Handbook of Contemporary Animism. Nova York: Routledge, 2014.

KVIDELAND, Reimund; SEHMSDORF, Henning. Scandinavian Folk Belief and Legend. Minneapolis: University of Minnesota Press, 1999. 
MARRANCA, Bonnie. Triptych: Isak Dinesen in Three Parts. Performing Arts Journal, v. 10, n. 2, p. 91-106, 1986. DOI: https://doi.org/10.2307/3245621.

STARHAWK, Miriam Simos. Magia, visão e ação. Tradução de Adriana Rinaldi e Jamille Pinheiro Dias. Revista do Instituto de Estudos Brasileiros, São Paulo, n. 69, p. 52-65, abr. 2018.

DOI: https://doi.org/10.11606/issn.2316-901X.v0i69p52-65.

STENGERS, Isabelle. Reativar o animismo. Tradução de Jamille Pinheiro Dias. Belo Horizonte: Edições Chão da Feira, 2017.

WEED, Merry. Märchen and Legend Techniques of Narration in Two 'Tales' of Isak Dinesen. Journal of the Folklore Institute, v. 15, n. 1, p. 23-44, janeiro-abril, 1978.

YACOBI, Tamar. Plots of Space: World and Story in Isak Dinesen. Poetics Today, v. 12, n. 3, p. 447-493, outono 1991.

Recebido em: 15/06/2020

Aceito em: 24/08/2020 